\title{
THE PHYSIOLOGIC CLOSURE OF THE DUCTUS ARTERIOSUS IN THE NEWBORN INFANT 1, 2
}

\author{
By FREDERIC L. ELDRIDGE ${ }^{3}$ AND HERBERT N. HULTGREN 4 with THE \\ TECHNICAL ASSISTANCE OF MARY E. WIGMORE
}

\author{
(From the Department of Medicine of the Stanford University School of Medicine, \\ San Francisco, Calif.)
}

(Submitted for publication November 18, 1954; accepted March 10, 1955)

The exact time of functional closure of the ductus arteriosus in the newborn human infant has remained a matter of speculation for many years. Studies of human anatomical specimens have shown that complete morphologic closure requires from four to eight weeks (1-5).

Animal experiments have been the main approach to the study of functional closure. All workers agree that at the time of birth, but before the onset of respiration and inflation of the lungs, the pressure in the pulmonary artery is equal to or greater than the pressure in the aorta and that a considerable portion of the output of the right ventricle passes through the ductus into the descending aorta. Most workers agree that in animals, with the onset of respiration, there occurs, within a few minutes, a rapid fall in pulmonary artery pressure so that blood no longer flows through the ductus into the aorta. However, Everett and Johnson (6) by injecting radioactive material into the right ventricle and studying the amount appearing in the dorsal aorta distal to the ductus in newborn puppies felt that the flow through the ductus into the aorta may persist for as long as nine hours after birth.

There is less agreement about the mechanism of this early functional closure of the ductus. Kennedy and Clark (7-9) observed prompt closure of the guinea pig ductus by muscular contraction during oxygen breathing, but Barron (10) could not corroborate this effect of oxygen in the lamb fetus. Other workers who have studied the closure of the ductus in the newborn lamb by

\footnotetext{
1 This study was aided by grants from the San Francisco Heart Association and the Fuller Foundation.

2 Presented in part at the Forty-Sixth Annual Meeting of the American Society for Clinical Investigation, Atlantic City, New Jersey, May 4, 1954.

3 Evelyn Neizer Fellow in Medicine.

4 Scholar in Medical Science-John and Mary $R$. Markle. Foundation.
}

angiography suggested that prompt closure occurred by muscular contraction within a few minutes after birth and that occasionally, after initial closure, the ductus may reopen (11-13).

Recently careful studies in lambs have been made by Dawes, Mott, Widdicombe, and Wyatt (14) and Ardran, Dawes, Prichard, Reynolds, and Wyatt (15). They employed the technic of cineangiography as well as intravascular pressure measurements and blood oxygen analyses. An immediate fall in pulmonary artery pressure and pulmonary vascular resistance accompanied by a great increase in the velocity of blood flow through the pulmonary circuit was found to occur with inflation of the lungs. The fall in pulmonary artery pressure was accompanied by a reversal of the flow through the ductus. The ductus was not observed to close during the course of these observations which lasted up to 90 minutes after birth.

Fewer experimental data are available regarding the closure of the ductus in the human. This, however, has not impeded the free application of results of animal experiments to the human despite words of caution by careful investigators (12). However, it is generally agreed that, as in animals, a physiologic pulmonary hypertension is present in the human fetus at the time of birth and before inflation of the lungs, but little is known about the changes in the circulation through the ductus and the lungs that occur with the onset of respiration. Patten $(4,16)$ has suggested that the circulatory adjustments in the human at birth may be more gradual than the abrupt alterations that occur in animals. This concept is based upon careful post-mortem anatomic measurements made in a large number of stillborn fetuses and newborn infants which demonstrate a well-developed pulmonary circulation at the time of birth and a gradual transition in the size of the vessels to adult 
relationships during the first two to three months of life.

The most important experimental studies of the closure of the human ductus have utilized the technic of angiography. Using retrograde aortography, Keith and Forsyth (17) found in two infants five days of age that no contrast medium entered the ductus from the aorta and concluded that functional closure was complete. Using venous angiography, Lind and Wegelius (18) found the ductus to be patent in six infants immediately after birth, and in "some other instances to have closed a few hours after birth." Retrograde aortography in two infants, two and six hours after birth, disclosed no contrast medium going through the ductus from the aorta into the pulmonary artery. However, in a later presentation (19) Lind described the results of venous angiography in 10 newborns studied within 12 hours after birth. In none of these cases was the ductus arteriosus visualized. Johnsson (20) noted one instance of a cyanotic newborn infant in whom ductal flow from pulmonary artery to aorta was demonstrated by angiography, and in whom cyanosis had disappeared one week later at which time angiography revealed no venoarterial ductal shunt.

These conflicting results indicate that the exact time of functional closure of the human ductus is still unsettled but that, at least in some infants, the ductus may be patent during the first few hours of life and that it may be the site of a venoarterial shunt of considerable magnitude. The present study was stimulated by these studies and by the observation that infants in the neonatal period occasionally show cyanosis of the lower part of the body but not of the upper portion. Regional cyanosis of this type has been observed in older children and adults who have a patent ductus arteriosus with pulmonary hypertension and a veno-arterial or "reversed" shunt through the ductus $(21,22)$. Due to this shunt of venous blood through the ductus to the descending aorta the arterial oxygen saturation is lower in the feet than in the hands. We believed that if a similar shunt were present in the newborn, it would continue as long as the ductus remained patent and the pressure in the pulmonary artery exceeded that in the aorta. To examine this possibility we have carried out 66 studies on 60 infants of vary- ing ages. The method of study was based upon determinations of the oxygen content of blood samples obtained from the upper and lower extremities.

\section{METHODS}

Arterialized capillary blood samples were collected from a finger of the right hand and from the toe of either foot. The right hand was selected rather than the left since occasionally the orifice of the left subclavian artery may lie opposite the ductus and, in the presence of a ductal veno-arterial shunt, allow some unsaturated blood to enter the left arm (23). The technic of sampling has been previously described (24). The extremities were warmed by hot moist compresses for five minutes and a deep incision made in the fleshy tip of the digit by a sharp scalpel blade. This usually produced from 0.5 to $1.0 \mathrm{ml}$. of blood in about 60 seconds. The samples were then chilled and analyses made within a few hours for oxygen contents and capacities by the Roughton-Scholander micro gasometric method for estimation of blood oxygen (25). Oxygen capacities were determined in all but 5 samples, where the quantity was insufficient to perform the analysis. In these specimens the oxygen capacity was calculated from the hemoglobin content of the sample. Estimated values for dissolved oxygen were subtracted from these figures, and the results expressed in terms of per cent oxygen saturation. Samples collected and analyzed in this manner have been shown to be identical in oxygen content to simultaneously drawn arterial samples (24). The blood thus obtained probably comes from small arterioles or arteries since the blood flow is rapid and occasionally can be seen to "spurt" in synchrony with the radial pulse, and if a blood pressure cuff placed around the arm is inflated to diastolic pressure during the warming of the hand and the sampling period, the hematocrit and oxygen saturation of the sample are unchanged (26). This would not be the case if capillary or venous blood were being obtained.

Most infants cried during the sampling period and were indeed encouraged to cry because continuous crying would minimize the gross differences in ventilation which might occur in the change from quiet to crying state. Since the samples were not taken simultaneously and in order to randomize the effect of crying on the samples, the foot and the hand were alternated as the site of the first sample. Analysis of the data obtained revealed no variations in hand-foot oxygen saturations that could be ascribed to whether the hand or foot sample was obtained first.

As part of the study, a careful auscultation of the heart was performed on all infants, and a note made of the presence or absence of cyanosis of any part of the body.

\section{OBSERVATIONS}

In 57 out of the 66 studies the blood sample from the right hand had an oxygen saturation of 
90 per cent or more (Tables I and II). This indicates that true arterial blood had been obtained and that the sampling technic and methods of analysis were adequate. The nine cases in which an oxygen saturation of less than 90 per cent was obtained from the right hand showed levels only slightly below 90 per cent. They were: 87.7,
$88.8,87.0,86.0,87.4,89.8,86.6,88.8$, and 85.4 per cent saturation. The ages of these infants were 40 minutes, $1 \frac{1}{2}$ hours, $171 / 2$ hours, $201 / 2$ hours, $61 / 2$ months, 8 months, 9 months, 10 months, and 10 months, respectively.

A comparison of the blood oxygen saturation of the right hand with that of the foot in 62 studies

TABLE I

Hand-foot oxygen saturation differences and magnitude of ductal veno-arterial shunt in 43 studies performed on 37 infants within five days after birth*

\begin{tabular}{|c|c|c|c|c|c|c|c|c|c|}
\hline \multirow[b]{2}{*}{ Infant } & \multirow[b]{2}{*}{$\begin{array}{c}\text { Age } \\
\text { hours }\end{array}$} & \multicolumn{3}{|c|}{ Right hand } & \multicolumn{3}{|c|}{ Foot } & \multirow{2}{*}{$\begin{array}{c}\text { Difference in } \\
\% \text { saturation } \\
\text { Hand minus foot } \\
\text { +Foot saturation } \\
\text { lower } \\
\text {-Foot saturation } \\
\text { higher }\end{array}$} & \multirow{2}{*}{$\begin{array}{c}\text { Significant } \\
\text { veno- } \\
\text { arterial } \\
\text { shunt } \\
\% \text { of de- } \\
\text { scending } \\
\text { aorta flow } \\
\text { (estimated) }\end{array}$} \\
\hline & & $\begin{array}{l}\text { Oxygen } \\
\text { content } \\
\text { ml./100 } \\
m l . b l o o d\end{array}$ & $\begin{array}{l}\text { Oxygen } \\
\text { capacity } \\
\text { ml./100 } \\
\text { ml. blood }\end{array}$ & $\begin{array}{l}\text { Oxygen } \\
\text { saturation } \\
\text { per cent }\end{array}$ & $\begin{array}{l}\text { Oxygen } \\
\text { content } \\
\text { ml./100 } \\
m l . b l o o d\end{array}$ & $\begin{array}{c}\text { Oxygen } \\
\text { capacity } \\
\text { ml./100 } \\
\text { ml.blood }\end{array}$ & $\begin{array}{c}\text { Oxygen } \\
\text { saturation } \\
\text { per cent }\end{array}$ & & \\
\hline 1 & $\frac{2}{3}$ & 19.35 & 22.13 & 87.7 & 19.73 & 22.47 & 87.4 & +0.3 & 一 \\
\hline 2 & $1^{3}$ & 21.51 & 22.77 & 94.4 & 21.06 & 23.33 & 90.4 & +4.0 & - \\
\hline 3 & 1 & 20.04 & 22.22 & 90.3 & 19.59 & 23.43 & 83.5 & $\begin{array}{r}+6.8 \\
+\end{array}$ & 37 \\
\hline 4 & $1 \frac{1}{2}$ & 23.11 & 25.13 & 92.0 & 22.22 & 25.48 & 87.2 & $\begin{array}{r}4.8 \\
+4.8\end{array}$ & - \\
\hline 5 & $1 \frac{1}{2}$ & 18.86 & 21.22 & 88.8 & 19.76 & 24.15 & 81.8 & +7.0 & 38 \\
\hline 6 & $1 \frac{1}{2}$ & 23.98 & 25.68 & 93.4 & 22.19 & 26.29 & 84.4 & $\begin{array}{r}+9.0 \\
+\end{array}$ & 58 \\
\hline 7 & $1 \frac{1}{2}$ & 22.09 & 23.42 & 94.4 & 21.36 & 23.86 & 89.4 & +5.0 & 29 \\
\hline 8 & $1 \frac{2}{3}$ & 17.42 & 18.90 & 92.2 & 16.15 & 19.36 & 83.4 & $\begin{array}{r}8.8 \\
+8.8\end{array}$ & 42 \\
\hline 9 & $2^{3}$ & 20.33 & 21.68 & 93.7 & 17.96 & 21.76 & 82.7 & +11.0 & 59 \\
\hline 10 & $2 \frac{1}{2}$ & 21.77 & 24.10 & 90.3 & 21.91 & 24.20 & 90.5 & -0.2 & - \\
\hline 11 & $2 \frac{1}{2}$ & 24.63 & 26.96 & 91.4 & 23.52 & 26.96 & 87.3 & +4.1 & - \\
\hline 12 & $2 \frac{3}{4}$ & 26.30 & 27.56 & 95.5 & 27.00 & 27.62 & 97.7 & -2.2 & - \\
\hline 13 & $2 \frac{3}{4}$ & 23.50 & 25.91 & 90.7 & 22.70 & 25.65 & 88.6 & +2.1 & - \\
\hline 14 & 3 & 23.68 & 24.62 & 96.2 & 23.03 & 24.12 & 95.6 & +0.6 & - \\
\hline 15 & $3 \frac{1}{2}$ & 27.68 & 29.08 & 95.2 & 25.63 & 28.08 & 91.3 & +3.9 & - \\
\hline 16 & $4 \frac{1}{2}$ & 24.40 & 26.12 & 93.5 & 23.99 & 26.19 & 91.6 & +1.9 & - \\
\hline 17 & 62 & 24.64 & 26.71 & 92.3 & 23.45 & 26.45 & 88.7 & +3.6 & - \\
\hline 18 & $6 \frac{1}{2}$ & 17.98 & 19.32 & 93.1 & 17.94 & 19.04 & 94.2 & -0.9 & - \\
\hline 19 & $11 \frac{1}{2}$ & 22.19 & 24.31 & 91.3 & 22.34 & 24.38 & 91.5 & -0.2 & - \\
\hline 20 & 12 & 18.02 & 19.28 & 93.5 & 17.93 & 19.69 & 90.8 & +2.7 & - \\
\hline 21 & $14 \frac{1}{2}$ & 26.65 & 28.88 & 92.3 & 27.62 & 29.45 & 93.8 & -1.5 & - \\
\hline 22 & $17 \frac{1}{2}$ & 17.12 & 19.67 & 87.0 & 17.08 & 19.35 & 88.3 & -1.3 & - \\
\hline 23 & 20 & 26.34 & 27.10 & 97.2 & 25.31 & 27.87 & 90.7 & +6.5 & 43 \\
\hline 24 & 21 & 19.18 & 22.29 & 86.0 & 18.76 & 22.29 & 84.0 & +2.0 & - \\
\hline 25 & 25 & 24.53 & 26.22 & 93.5 & 23.72 & 26.22 & 90.4 & +3.1 & - \\
\hline 26 & 27 & 22.55 & 24.92 & 90.5 & 20.72 & 25.12 & 82.5 & +8.0 & 70 \\
\hline 27 & 33 & 17.39 & 18.39 & 94.5 & 17.25 & 18.98 & 90.9 & +3.6 & - \\
\hline 28 & 42 & 22.80 & 24.15 & 94.3 & 23.05 & 25.12 & 92.0 & +2.3 & - \\
\hline $29(9)$ & 45 & 18.37 & 19.56 & 94.0 & 16.33 & 20.58 & 79.5 & +14.5 & 72 \\
\hline $30(3)$ & 47 & 20.70 & 22.43 & 92.2 & 18.71 & 22.91 & 81.7 & +10.5 & 58 \\
\hline $31(6)$ & 49 & 26.28 & 28.16 & 93.5 & 25.47 & 27.94 & 91.2 & +2.3 & - \\
\hline 32 & 50 & 23.78 & 25.35 & 93.8 & 23.61 & 25.20 & 93.7 & +0.1 & 一 \\
\hline 33 & 57 & 18.48 & 20.18 & 91.7 & 18.76 & 19.79 & 94.8 & -3.1 & 一 \\
\hline 34 & 60 & 24.61 & 26.55 & 92.7 & 24.92 & 26.07 & 95.5 & -2.8 & - \\
\hline 35 & 68 & 21.35 & 22.81 & 93.5 & 21.25 & 23.80 & 89.4 & +4.1 & - \\
\hline & 81 & 21.46 & 23.85 & 90.0 & 21.88 & 25.03 & 87.3 & +2.7 & - \\
\hline 37 & 85 & 18.09 & 18.90 & 95.7 & 18.96 & 19.89 & 95.3 & +0.2 & 一 \\
\hline 38 & 94 & 26.49 & 28.53 & 93.0 & 28.27 & 29.97 & 94.3 & -1.3 & - \\
\hline & 96 & 25.39 & 27.14 & 93.6 & 24.53 & 26.05 & 94.1 & -0.5 & - \\
\hline $40(6)$ & 103 & 22.87 & 24.59 & 93.2 & 22.24 & 24.03 & 92.5 & +0.7 & - \\
\hline & 108 & 22.93 & 24.50 & 93.6 & 23.04 & 24.92 & 92.6 & +1.0 & - \\
\hline $42(9)$ & 117 & 18.15 & 19.80 & 91.7 & 17.70 & 19.37 & 91.3 & +0.4 & - \\
\hline $43(2)$ & 120 & 22.26 & 23.93 & 93.0 & 22.17 & 24.22 & 91.5 & +1.5 & - \\
\hline \multirow{3}{*}{\multicolumn{2}{|c|}{$\begin{array}{l}\text { Mean } \\
\text { Range }\end{array}$}} & 22.08 & 23.84 & 92.6 & 21.65 & 24.10 & 89.7 & +2.9 & \\
\hline & & 17.12 to & 18.39 to & 87.0 to & 16.15 to & 18.98 to & 79.5 to & -3.1 to & \\
\hline & & 27.68 & 29.08 & 97.2 & 27.62 & 28.08 & 97.7 & +14.5 & \\
\hline \multicolumn{2}{|c|}{ Standard deviation } & \pm 2.96 & \pm 2.98 & \pm 2.3 & \pm 3.06 & \pm 2.92 & \pm 4.3 & \pm 3.8 & \\
\hline
\end{tabular}

* Repeat studies were performed in four infants. These are indicated by the number of the infant in parentheses following the repeat study. 
TABLE II

Hand-foot oxygen saturation differences determined in 19 infants from $3 \frac{1}{2}$ to 11 months old (control group)

\begin{tabular}{|c|c|c|c|c|c|c|c|c|}
\hline \multirow[b]{2}{*}{ Infant } & \multirow[b]{2}{*}{$\begin{array}{c}\text { Age } \\
\text { months }\end{array}$} & \multicolumn{3}{|c|}{ Right hand } & \multicolumn{3}{|c|}{ Foot } & \multirow{2}{*}{$\begin{array}{c}\text { Diff. in } \\
\text { per cent } \\
\text { saturation } \\
\text { Hand minus foot } \\
\text { +Foot saturation } \\
\text { lower } \\
\text {-Foot saturation } \\
\text { higher }\end{array}$} \\
\hline & & $\begin{array}{l}\text { Oxygen } \\
\text { content } \\
\text { ml./100 } \\
\text { ml.blood }\end{array}$ & $\begin{array}{l}\text { Oxygen } \\
\text { capacity } \\
\text { ml./100 } \\
\text { ml.blood }\end{array}$ & $\begin{array}{l}\text { Oxygen } \\
\text { saturation } \\
\text { per cent }\end{array}$ & $\begin{array}{l}\text { Oxygen } \\
\text { content } \\
m l . / 100 \\
m l . b l o o d\end{array}$ & $\begin{array}{l}\text { Oxygen } \\
\text { capacity } \\
\text { ml./100 } \\
\text { ml.blood }\end{array}$ & $\begin{array}{l}\text { Oxygen } \\
\text { saturation } \\
\text { per cent }\end{array}$ & \\
\hline 1 & $3 \frac{1}{2}$ & 13.58 & 15.08 & 90.1 & 13.34 & 15.08 & 88.6 & +1.5 \\
\hline 2 & $4^{2}$ & 15.07 & 15.95 & 94.5 & 15.27 & 15.91 & 95.8 & -1.3 \\
\hline 3 & $4 \frac{1}{2}$ & 12.53 & 13.60 & 92.1 & 12.34 & 13.61 & 90.7 & +1.4 \\
\hline 4 & $4 \frac{1}{2}$ & 13.06 & 14.42 & 90.5 & 13.67 & 15.13 & 90.3 & +0.2 \\
\hline 5 & $4 \frac{1}{2}$ & 13.89 & 14.67 & 94.7 & 14.29 & 15.43 & 92.7 & +2.0 \\
\hline 6 & $5^{2}$ & 14.55 & 15.60 & 93.3 & 14.28 & 15.11 & 94.6 & -1.3 \\
\hline 7 & 5 & 13.28 & 13.92 & 95.4 & 13.35 & 14.06 & 95.0 & +0.4 \\
\hline 8 & 5 & 13.76 & 14.40 & 95.5 & 12.97 & 14.17 & 91.6 & $\begin{array}{r}3.9 \\
+\end{array}$ \\
\hline 9 & 6 & 14.40 & 15.29 & 94.2 & 14.18 & 14.92 & 94.9 & -0.7 \\
\hline 10 & 6 & 10.20 & 10.74 & 94.9 & 10.57 & 11.19 & 94.3 & +0.6 \\
\hline 11 & $6 \frac{1}{2}$ & 11.14 & 12.76 & 87.4 & 10.88 & 11.84 & 92.0 & -4.6 \\
\hline 12 & 8 & 15.65 & 17.41 & 89.8 & 15.60 & 17.46 & 89.3 & +0.6 \\
\hline 13 & 8 & 14.40 & 15.97 & 90.2 & 14.35 & 16.31 & 88.0 & +2.2 \\
\hline 14 & 9 & 10.30 & 11.24 & 91.6 & 10.57 & 11.61 & 91.0 & +0.6 \\
\hline 15 & 9 & 13.51 & 15.60 & 86.6 & 14.71 & 16.66 & 88.3 & -1.7 \\
\hline 16 & 10 & 13.70 & 15.44 & 88.8 & 14.31 & 15.26 & 93.9 & -5.1 \\
\hline 17 & 10 & 12.68 & 14.86 & 85.4 & 13.82 & 15.93 & 86.7 & -1.3 \\
\hline 18 & $10 \frac{1}{2}$ & 16.33 & 17.47 & 93.5 & 16.22 & 16.96 & 95.7 & -2.2 \\
\hline 19 & $11^{2}$ & 15.10 & 15.57 & 97.0 & 14.78 & 15.66 & 94.5 & +2.5 \\
\hline \multirow{3}{*}{\multicolumn{2}{|c|}{$\begin{array}{l}\text { Mean } \\
\text { Range }\end{array}$}} & 13.53 & 14.74 & 91.9 & 13.66 & 14.85 & 92.0 & -0.1 \\
\hline & & 10.20 to & 10.74 to & 85.4 to & 10.57 to & 11.19 to & 86.7 to & -5.1 to \\
\hline & & 16.33 & 17.47 & 97.0 & 16.22 & 17.46 & 95.8 & +3.9 \\
\hline \multicolumn{2}{|c|}{ Standard deviation } & \pm 1.61 & \pm 1.70 & \pm 3.1 & \pm 1.58 & \pm 1.71 & \pm 2.8 & \pm 2.2 \\
\hline
\end{tabular}

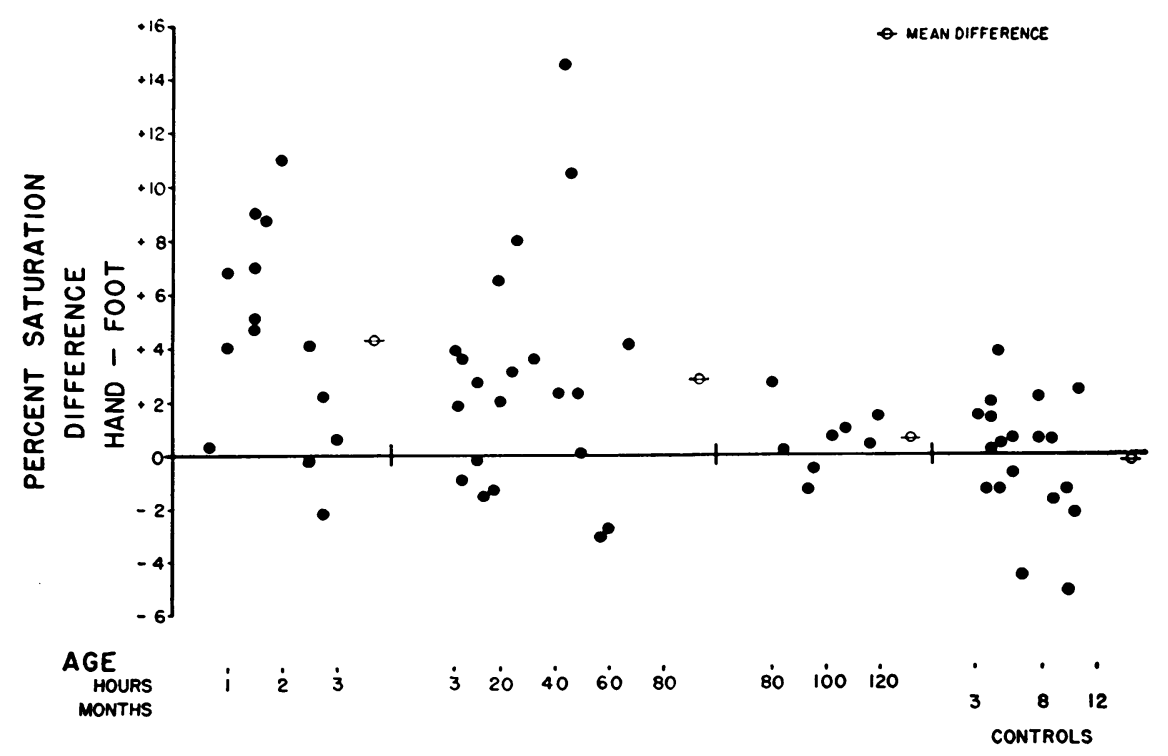

Fig. 1. Graphic Summary of Hand-Foot Oxygen Saturation Differences in 43 Studies on 37 Infants Performed within Five Days after Birth Compared with Control Values in 19 Older Children

Positive values in this and subsequent figures indicate cases in which the oxygen saturation in the foot is lower than that in the hand. The mean difference for each group is indicated just to the right of the oldest infant in the group. 
is shown in Tables I and II and graphically illustrated in Figure 1. For ease of presentation we have chosen to express the relationship between the oxygen saturations of blood from the upper and lower extremities as the hand saturation minus the foot saturation (hereafter referred to as the hand-foot difference); hence cases in which the foot saturation is lower will appear above the baseline of the graph and will have a positive value.

Nineteen infants aged $31 / 2$ months to 11 months who were free of cardiac or pulmonary disease that might affect arterial oxygen saturation served as controls (Table II). Since the ductus is anatomically closed by this age, all of these infants should have the same oxygen saturation in both hand and foot blood. In these cases, no hand-foot saturation difference of more than 5.1 per cent was observed.

A statistical evaluation of the data obtained from all four groups of infants studied is presented in Table III. It can be seen that there is a striking difference between the two groups of children less than 72 hours of age and the two groups of children older than 72 hours. The mean values are higher, and the variances are distinctly greater in the younger groups. The high variance (scatter) at the earlier ages is a reflection of the presence of a sizable fraction of the subjects giving large hand-foot differences, with many others giving near-zero values. The smaller variance in the later groups reflects the disappearance of high values, which may be interpreted as evidence of the disappearance of the ductal veno-arterial shunt within the first three days of life. The mean hand-foot difference for the 35 infants less than 72 hours old is 3.44 ; the mean hand-foot difference for the 27 infants older than 72 hours is .013 . The difference between

TABLE III

Statistical evaluation of the data from the four groups of infants

\begin{tabular}{ccccc}
\hline \hline & $\begin{array}{c}\text { Mean } \\
\text { hand-fot } \\
\text { difference } \\
\% \text { satu- } \\
\text { ration }\end{array}$ & $\begin{array}{c}\text { Standard } \\
\text { error of } \\
\text { mean }\end{array}$ & $\begin{array}{c}\text { Variance } \\
\text { of obser- } \\
\text { vations }\end{array}$ & $\begin{array}{c}\text { Sample } \\
\text { size } \\
\text { No. } \\
\text { infants }\end{array}$ \\
\hline 1 to 3 hrs. & 4.37 & 1.04 & 15.244 & 14 \\
3 to 72 hrs. & 2.82 & .94 & 18.73 & 21 \\
72 to 120 hrs. & .59 & .43 & 1.487 & 8 \\
$3 \frac{1}{2}$ to 11 mos. & -.10 & .52 & 5.318 & 19 \\
\hline
\end{tabular}

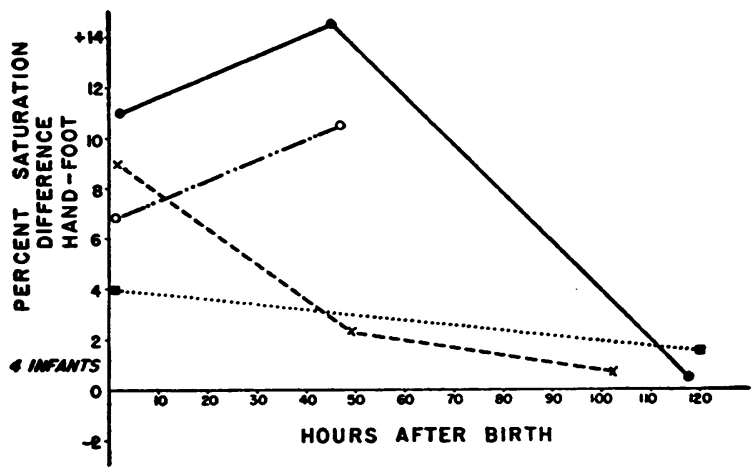

Fig. 2. Serial Measurements of Hand-Foot Oxygen Saturation Differences in Four Infants

these two values is statistically significant at the .001 level of significance, and thus can hardly be attributed merely to chance factors. It is important to note that it is not only the mean which is changing but that also the variability amongst the hand-foot differences is much greater at earlier ages. The variances of the paired groups also differ far more than chance alone would explain, 1 per cent significance by Bartlett's test (27).

These data suggest the presence of a venoarterial shunt through the ductus in a considerable number of infants during the first three days of life. If one accepts a 5 per cent hand-foot difference as probably certain evidence of a shunt ( since only one of the 19 control cases had a difference larger than this), then it can be seen that 5 out of 14 infants or 36 per cent of cases under three hours of age and 4 out of 21 infants or 19 per cent of cases from 3 to 72 hours of age had veno-arterial shunts while none of the children in the 72- to 120-hour group exhibited evidence of such a shunt. It should be pointed out that a 5 per cent difference in saturation between hand and foot indicates the presence of a veno-arterial shunt contributing about 30 per cent of the total blood flow in the descending aorta. From inspection of the data in Figure 1 it is apparent that several infants probably had smaller shunts because the majority of the values in the first two groups of infants lie above the zero line of the graph while the values for the older children are more evenly scattered above and below the zero line. This is also reflected by the differences in the variances shown in Table III.

Four infants who initially presented evidence of a veno-arterial shunt were studied more than once 
during the first five days of life. The differences in hand-foot saturation shortly after birth are shown in Figure 2, as are the differences with increasing age. All three infants followed to the age of five days lost evidence of veno-arterial shunts to the lower extremities, the one infant followed only to two days still maintained a large hand-foot difference.

The lower oxygen saturation of the foot blood as compared to that of the hand was often striking and obvious. Definite cyanosis of the feet as compared to the normal pink color of the hand was noted in almost all the infants with a handfoot difference in oxygen saturation of 8 per cent or over. Upon obtaining the blood samples, inspection of the two syringes frequently revealed the obvious darker color of the less saturated sample from the foot.

Heart murmurs were carefully sought for in these infants. A murmur was heard in only one case, a one and one-half-hour-old girl who had a hand-foot oxygen saturation difference of 7.0 per cent. The murmur was systolic in time, of moderate intensity, and was heard best in the pulmonic area.

\section{DISCUSSION}

It may be remotely possible that the greater hand-foot oxygen saturation difference in the first few days of life may reflect regional differences in the circulation between these two extremities so that venous blood was obtained in the samples from the foot but not from the hand. However, no consistent differences in rate of flow were noted between the extremities; the differences in saturation had disappeared by the third day of life, and no differences in saturation were noted in the controls so that it would appear that the samples obtained were equivalent to samples of arterial blood. Since a patent ductus arteriosus with veno-arterial shunt is the most probable circulatory cause for the observed differences in handfoot oxygen saturation, it is apparent that the above data have several important implications.

1. In the newborn human infant the ductus arteriosus is patent and is the site of a venoarterial shunt of moderate to considerable magnitude for at least three hours after birth in about 30 per cent of infants, and in a smaller percentage of infants up to two or three days of age. Crude calculations, assuming a systemic arteriovenous oxygen difference of $4 \mathrm{ml}$. per $100 \mathrm{ml}$. blood, indicate that this veno-arterial shunt may contribute as much as 72 per cent of the total blood flow in the descending aorta The right hand column in Table I shows the estimated percentage of descending aorta flow contributed by the right-toleft shunt through the patent ductus in infants having hand-foot oxygen saturation differences of 5 per cent or more. In the six infants up to three hours of age who showed significant shunts, the range was from 29 to 59 per cent of the descending aorta flow with a mean for these infants of 44 per cent. In the four infants, 3 to 72 hours of age, who showed shunts, the range was from 43 to 72 per cent with a mean of 61 per cent. Because of the limits of error of the technic, venoarterial shunts of less than 30 per cent of the total descending aorta flow could not be detected, and it may well be that a larger proportion of infants had shunts which were not detected in this study.

2. If a veno-arterial shunt occurs through the ductus, it follows that the pulmonary artery pressure must exceed or equal the pressure in the aorta as long as the shunt persists. Several studies $(28,29)$ have indicated that the femoral or brachial arterial pressure in the newborn infant is about $80 / 47 \mathrm{~mm}$. $\mathrm{Hg}$. If one subtracts $5 \mathrm{~mm}$. from the systolic level to allow for the "standing pressure wave" in the femoral artery (30), the pressure in the aorta of the newborn can be approximated at $75 / 47 \mathrm{~mm}$. Hg. Thus, the pulmonary artery pressure in the infants with ductal veno-arterial shunts must at some time in the heart cycle exceed this pressure although the magnitude of this difference in pressure is unknown. The size of the shunt and the pressure difference will also be related to the size of the ductus. With a relatively large ductus a large shunt may exist with little pressure difference. The influence of crying upon the pressure relationships and magnitude of the shunts is unknown. It is quite possible that the increase in intra-thoracic pressure associated with crying might cause a veno-arterial shunt to occur through the ductus where none was apparent at rest.

The cause of the disappearance of the venoarterial shunt, which is complete in most infants by the age of 72 hours, is not clear. Two possibilities exist: (a) the ductus may have closed so 
TABLE IV

Data on four infants before and after breathing 12 per cent oxygen

\begin{tabular}{|c|c|c|c|c|c|c|}
\hline Infant & $\begin{array}{c}\text { Age } \\
\text { hours }\end{array}$ & $\begin{array}{l}\text { Oxygen } \\
\text { mixture }\end{array}$ & $\begin{array}{c}\text { Oxygen } \\
\text { saturation \% } \\
\text { Right hand }\end{array}$ & $\begin{array}{c}\text { Oxygen } \\
\text { saturation } \% \\
\text { Foot }\end{array}$ & $\begin{array}{c}\text { Difference in } \\
\text { \% saturation } \\
\text { Hand minus foot } \\
\text { +Foot saturation } \\
\text { lower } \\
\text { - Foot saturation } \\
\text { higher }\end{array}$ & $\begin{array}{l}\text { Veno- } \\
\text { arterial } \\
\text { shunt } \\
\% \text { of de- } \\
\text { scending } \\
\text { aorta } \\
\text { flow }\end{array}$ \\
\hline A & $4 \frac{1}{2}$ & $\begin{array}{l}\text { Room air } \\
12 \% \mathrm{O}_{2}\end{array}$ & $\begin{array}{l}93.5 \\
85.2\end{array}$ & $\begin{array}{l}91.6 \\
79.0\end{array}$ & $\begin{array}{r}+1.9 \\
+6.2\end{array}$ & $\overline{39}$ \\
\hline B & 6 & $\begin{array}{l}\text { Room air } \\
12 \% \mathrm{O}_{2}\end{array}$ & $\begin{array}{l}92.3 \\
79.7\end{array}$ & $\begin{array}{l}88.7 \\
73.1\end{array}$ & $\begin{array}{r}+3.6 \\
+6.6\end{array}$ & $\begin{array}{l}24 \\
45\end{array}$ \\
\hline C & $6 \frac{1}{2}$ & $\begin{array}{l}\text { Room air } \\
12 \% \mathrm{O}_{2}\end{array}$ & $\begin{array}{l}93.1 \\
83.7\end{array}$ & $\begin{array}{l}94.0 \\
78.7\end{array}$ & $\begin{array}{r}0.9 \\
+\quad 5.0\end{array}$ & $\overline{24}$ \\
\hline D & $14 \frac{1}{2}$ & $\begin{array}{l}\text { Room air } \\
12 \% \mathrm{O}_{2}\end{array}$ & $\begin{array}{l}92.3 \\
57.4\end{array}$ & $\begin{array}{l}93.8 \\
47.3\end{array}$ & $\begin{array}{r}-1.5 \\
+10.1\end{array}$ & $\overline{73}$ \\
\hline
\end{tabular}

that it will not transmit blood in either direction, or (b) the pressure in the pulmonary artery may have fallen to a level below the aortic pressure thereby causing the veno-arterial shunt to disappear but making an arteriovenous shunt possible. The latter has been the.case in the animal studies of Ardran and co-workers (15), where the pulmonary resistance and pressure fell markedly within 15 minutes of birth, thereby causing an arteriovenous shunt to develop.

To investigate these possibilities, hand and foot blood samples were collected in the manner described above from four infants before and at the end of a six-minute period of hypoxia. This was produced by having the infant breathe, by means of a face mask, a 12 per cent oxygen mixture. While breathing room air, there was no hand-foot difference of greater than 3.6 per cent in the infants studied (Table IV).

A significant degree of arterial unsaturation was produced by the low oxygen breathing since the oxygen saturation of hand blood fell in each case, the mean fall being 10 per cent, corresponding to a drop in oxygen tension of about $20 \mathrm{~mm}$. $\mathrm{Hg}$. In each case this resulted in an increase of the hand-foot difference indicating the re-establishment of the veno-arterial shunt through the ductus (Figure 3). One infant (Infant D, Table IV) had a marked generalized fall of oxygen saturation during the low oxygen breathing-from an initial value of 92 per cent saturation in the right hand to a value of 57 per cent. This was accompanied by visible, generalized cyanosis and somnolence. After room air breathing was resumed, the cyanosis promptly disappeared and no subsequent ill effects were noted. A similar precipitous fall in oxygen saturation in one patient was noted by Burchell, Swan, and Wood during the breathing of low oxygen mixtures by an older patient with a patent ductus and pulmonary hypertension (23). The mechanism of the response is unknown. Hypoventilation (31) or intense pulmonary vasoconstriction with a large venoarterial ductal shunt associated with a right- to left-shunt through a patent foramen ovale are possibilities. Because of this hazard of induced hypoxia in infants, further studies were not carried out.

The above data suggest that the cause of the disappearance of the hand-foot oxygen saturation difference is a fall in pulmonary artery pressure

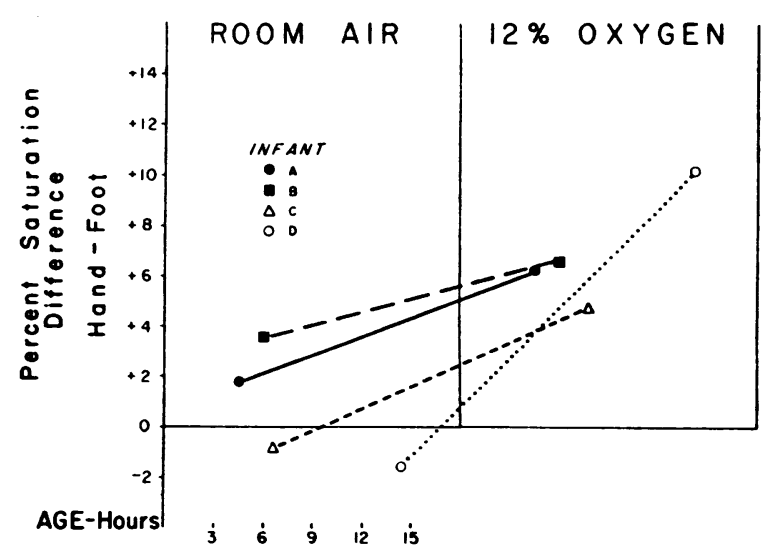

Fig. 3. Effect of Breathing 12 Peg Cent Oxygen upon Hand-Foot Oxygen Difmerences in Four NewBORN INFANTS 
to a level below the aortic pressure rather than actual closure of the ductus arteriosus. The infant pulmonary vascular bed is apparently similar to that of the adult in its response to hypoxia, which causes an increase in pulmonary vascular resistance and a rise in pulmonary artery pressure. This is sufficient to re-establish the venoarterial shunt through the ductus. Similar findings were noted by Lind and Wegelius (18) in two cases of neonatal asphyxia who gave angiographic evidence of a patent ductus with pulmonary artery to aorta flow. It is remotely possible that ductal closure has occurred by muscular contraction and that hypoxia has caused the ductus to reopen by muscular relaxation. One must still, however, assume that the pulmonary artery pressure has either remained higher than the aortic pressure since birth or that it has become elevated by the hypoxia. This problem will not be settled until further proof of the closure of the human ductus by muscular contraction is available. Whether muscular activity is involved in the process or not, these data raise the interesting question of the relationship of hypoxia to permanent patency, since there have been several reports of increased incidence of patent ductus arteriosus in children and adults at high altitudes where a consistently low oxygen tension is experienced $(32,33)$.

It is apparent that this study has not demonstrated the actual time of physiologic closure of the ductus, but it has shown that in some cases the ductus may remain open much longer than has previously been supposed. The fact that the veno-arterial shunt persists in some infants for several days indicates that the fall of pulmonary artery pressure from neonatal levels is variable and may depend upon other factors besides inspired oxygen tension.

3. The difference in oxygen saturation between blood samples from the upper and lower extremities in the newborn has another very practical implication. Many studies have been made by various workers in an effort to study the arterial oxygen saturation of the newborn. In many of these studies foot or umbilical artery blood has been used (34-37). In one of these studies (38) conclusions were drawn as to the chemical control of respiration in the newborn infant. The oxygen saturations thus obtained, in many in- stances, may have been low because of the venoarterial shunt at the ductus, as demonstrated by the data in this paper. Values for carbon dioxide content and $\mathrm{pH}$ in the foot blood would also be different from true arterial blood by virtue of this venous admixture. Several studies using oximeters placed on the ears $(39,40)$ or foreheads (41) of newborn infants have thus avoided this venous admixture from the ductus and have shown arterial saturations comparable to those found in the right hands of the infants in this study. It is apparent therefore that in order to obtain true arterial blood from the newborn and to avoid the venous admixture due to the ductus, samples should be obtained from either the right upper extremity or the right ear lobe.

4. The absence of heart murmurs in these infants with blood flow through the ductus is of interest. Only one of the 43 newborn infants had a murmur, which was systolic in time. This absence of murmurs is comparable to the findings of Lyon, Rauh, and Stirling' (42), who found murmurs in only a small percentage of newborn infants. A few of their cases showed at 24 hours of age a murmur which disappeared in a few days. We can make the same conclusion that they did, "that the remnants of fetal circulation rarely produce cardiac murmurs."

\section{SUM MARY}

1. Hand-foot oxygen saturations have been determined in 60 infants from 40 minutes to 11 months after birth. In a majority of infants under three hours of age, and in many infants under three days of age, the foot saturations are significantly lower than hand saturations.

2. Hypoxia will increase or re-establish the hand-foot oxygen saturation difference in infants up to 15 hours of age who have minimal initial hand-foot differences.

3. The following implications have been drawn from these studies:

(a) The ductus arteriosus may be open in the newborn human infant.

(b) Under these circumstances it is the site of a veno-arterial shunt of considerable magnitude which persists in a significant number of infants up to 72 hours of life. 
(c) A high pulmonary artery pressure is present at birth and persists as long as the veno-arterial ductal shunt exists.

(d) The cessation of the veno-arterial ductal shunt is probably due to a fall in pulmonary artery pressure below the pressure in the aorta, rather than to an actual closure of the ductus.

(e) Studies of newborn blood gases, in which heel blood has been used, are not representative of true arterial blood since an admixture of venous blood from the ductus may be present.

(f) Heart murmurs are rarely heard in the newborn in spite of the early physiologic patency of the ductus arteriosus.

\section{ACKNOWLEDGMENT}

The authors are indebted to Lincoln Moses, Ph.D., for his assistance in the statistical evaluation of the data.

\section{REFERENCES}

1. Scammon, R. E., and Norris, E. H., On the time of the post-natal obliteration of the fetal blood-passages (foramen ovale, ductus arteriosus, ductus venosus). Anat. Rec., 1918, 15, 165.

2. Patten, B. M., The changes in circulation following birth. Am. Heart J., 1930, 6, 192.

3. Christie, A., Normal closing time of the foramen ovale and the ductus arteriosus, an anatomic and statistical study. Am. J. Dis. Child., 1930, 40, 323.

4. Patten, B. M., Growth and Development of the Child: Part II, Anatomy and Physiology. White House Conference on Child Health and Protection. New York, The Century Co., 1933, pp. 277-283.

5. Jager, B. V., and Wollenman, O. J., Jr., An anatomical study of the closure of the ductus arteriosus. Am. J. Path., 1942, 18, 595.

6. Everett, N. B., and Johnson, R. J., A physiological and anatomical study of the closure of the ductus arteriosus in the dog. Anat. Rec., 1951, 110, 103.

7. Kennedy, J. A., and Clark, S. L., Observations on the ductus arteriosus of the guinea pig in relation to its method of closure. Anat. Rec., 1941, 79, 349.

8. Kennedy, J. A., and Clark, S. L., Observations on the physiological reactions of the ductus arteriosus. Am. J. Physiol., 1942, 136, 140.

9. Kennedy, J. A., A new concept of the cause of patency of the ductus arteriosus. Am. J. M. Sc., 1942, 204, 570.

10. Barron, D. H., The changes in fetal circulation at birth. Physiol. Rev., 1944, 24, 277.

11. Barclay, A. E., Barcroft, J., Barron, D. H., and Franklin, K. J., A radiographic demonstration of the circulation through the heart in the adult and in the foetus, and the identification of the ductus arteriosus. Am. J. Roentgenol., 1942, 47, 678.
12. Barclay, A. E., Franklin, K. J., and Prichard, M. M. L., The Foetal Circulation and Cardiovascular System, and the Changes That They Undergo at Birth. Springfield, Ill., Charles C Thomas, 1944.

13. Barcroft, J., Researches on Pre-natal Life. Oxford, Blackwell Scientific Publications, 1946.

14. Dawes, G. S., Mott, J. C., Widdicombe, J. G., and Wyatt, D. G., Changes in the lungs of the newborn lamb. J. Physiol., 1953, 121, 141.

15. Ardran, G. M., Dawes, G. S., Prichard, M. M. L., Reynolds, S. R. M., and Wyatt, D. G., The effect of ventilation of the foetal lungs upon the pulmonary circulation. J. Physiol., 1952, 118, 12.

16. Patten, B. M., The changes in circulation following birth. Am. Heart J., 1930, 6, 192.

17. Keith, J. D., and Forsyth, C., Aortography in infants. Circulation, 1950, $2,907$.

18. Lind, J., and Wegelius, C., Changes in the circulation at birth. Acta paediat., 1952, 41, 495.

19. Lind, J., Disturbances in the postnatal closures of various blood vessels and channels and their relationship to asphyxia neonatorum. Symposium on Anoxia of the New-born Infant, The Council for International Organizations of Medical Sciences. Oxford, Blackwell Scientific Publications, 1953.

20. Quoted by Ekström, G., The surgical treatment of patent ductus arteriosus. A clinical study of 290 cases. Acta chir. Scandinav., 1952, Supp. 169.

21. Dammann, J. F., Jr., Berthrong, M., and Bing, R. J., Reverse ductus. A presentation of the syndrome of patency of the ductus arteriosus with pulmonary hypertension and a shunting of blood flow from pulmonary artery to aorta. Bull. Johns Hopkins Hosp., 1953, 92, 128.

22. Hultgren, H., Selzer, A., Purdy, A., Holman, E., and Gerbode, F., The syndrome of patent ductus arteriosus with pulmonary hypertension. Circulation, 1953, 8, 15.

23. Burchell, H. B., Swan, H. J. C., and Wood, E. H., Demonstration of different effects on pulmonary and systemic arterial pressure by variation in oxygen content of inspired air in patients with patent ductus arteriosus and pulmonary hypertension. Circulation, 1953, 8, 681.

24. Hultgren, H. N., and Hackett, A. J., Determination of the oxygen content of capillary blood in congenital heart disease. Pediatrics, 1950, 6, 93.

25. Roughton, F. J. W., and Scholander, P. F., Micro gasometric estimation of the blood gases. I. Oxygen. J. Biol. Chem., 1943, 148, 541.

26. Hultgren, $H$. N., Unpublished observations.

27. Dixon, W., and Massey, F., Introduction to Statistical Analysis. New York, McGraw-Hill Book Co., Inc., 1951, p. 90.

28. Haselhorst, G., and Stromberger, K., Uber den Gasgehalt des Nabelschnurblutes vor und nach der Geburt des Kindes und über den Gasaustausch in der Plazenta. Ztschr. f. Geburtsch. u. Gynäk., 1932, 102, 16. 
29. Woodbury, R. A., Robinow, M., and Hamilton, W. F., Blood pressure studies on infants. Am. J. Physiol., 1938, 122, 472.

30. Hamilton, W. F., and Dow, P., An experimental study of the standing waves in the pulse propagated through the aorta. Am. J. Physiol., 1939, 125, 48.

31. Miller, H. C., and Behrle, F. C., The effects of hypoxia on the respiration of newborn infants. Pediatrics, 1954, 14, 93.

32. Dexter, L., Congenital defects of the heart in high altitudes. New England J. Med., 1952, 247, 851.

33. Alzamora, V., Rotta, A., Battilana, G., Abugattas, R., Rubio, C., Bouroncle, J., Zapata, C., SantaMaria, E., Binder, T., Subiria, R., Paredes, D., Pando, B., and Graham, G. G., On the possible influence of great altitudes on the determination of certain cardiovascular anomalies. Preliminary Report. Pediatrics, 1953, 12, 259.

34. Eastman, N. J., Foetal blood studies. I. The oxygen relationships of umbilical cord blood at birth. Bull. Johns Hopkins Hosp., 1930, 47, 221.

35. Smith, C. A., and Kaplan, E., Adjustment of blood oxygen levels in neonatal life. Am. J. Dis. Child., 1942, 64, 843.

36. Taylor, E. S., Govan, C. D., and Scott, W. C., Oxygen saturation of the blood of the newborn, as affected by maternal anesthetic agents. Am. J. Obst. \& Gynec., 1951, 61, 840.
37. Watts, J., Henderson, H., Kaump, D. H., and Davis, R. M., Oxygen studies of the arterial blood in newborn infants. Am. J. Obst. \& Gynec., 1951, 61, 1025.

38. Graham, B. D., and Wilson, J. L., Chemical control of respiration in newborn infants. Am. J. Dis. Child., 1954, 87, 287.

39. Crehan, E. L., Kennedy, R. L. J., and Wood, E. H., Symposium on in vivo photometry of blood in human beings. A study of the oxygen saturation of arterial blood of normal newborn infants by means of modified photo-electric oximeter: preliminary report. Proc. Staff Meet., Mayo Clin., 1950, 25, 392

40. Crehan, E. L., Kennedy, R. L., and Wood, E. H., Study of oxygen saturation of arterial blood of normal newborn infants by means of a modified photoelectric oximeter. Am. J. Dis. Child., 1950; 80, 511.

41. Jonxis, J. H. B., Some results of the registration of the oxygen saturation of young infants' skin blood which has been arterialized by means of histamine. Registration done with Brinkman method. Symposium on Anoxia of the New-born Infant. Council for International Organizations of Medical Sciences. Oxford, Blackwell Scientific Publications, 1953.

42. Lyon, R. A., Rauh, L. W., and Stirling, J. W., Heart murmurs in newborn infants. J. Pediat., 1940, 16, 310.

\section{SPECIAL NOTICE TO SUBSCRIBERS}

Post Offices will no longer forward the Journal when you move.

Please notify The Journal of Clinical Investigation, Business Office, 622 West 168th Street, New York 32, N. Y. at once when you have a change of address, and do not omit the zone number if there is one. 